\title{
A retórica dos vigilantes: autoria online
}

\section{Luiz Antonio Ferreira}

Doutor em Educação pela Universidade de São Paulo (USP) e docente do Programa de Estudos Pós-Graduação da Pontifícia Universidade Católica de São Paulo (PUC/SP), Brasil. luizanferreira@terra.com.br

Resumo: Este artigo pretende refletir sobre formas e condições de autoria nos meios digitais para realçar o caráter operativo, vigilante e fluido que caracteriza 0 ato de argumentar na Internet. A partir das concepções de isegoria, kairós e comunidades discursivas, três categorias discursivas se delineiam e, a partir delas, duas classificações de vocação enunciativa se conformam: o autor-nominado e o autor-apócrifo. Os princípios teóricos da Retórica e da Nova retórica sustentam a reflexão. Considera-se, por fim, a autoria virtual como um exercício privilegiado de difusão do docere, do movere e do delectare.

Palavras-chave: Autoria. Virtualidade. Argumentação. Retórica.

Abstract: This article intends to reflect on forms and conditions of authorship in digital media to highlight the operative, vigilant and fluid character that characterizes the act of arguing on the Internet. From the conceptions of isegoria, kairós and discursive communities, three discursive categories are delineated and, from them, two classifications of enunciative vocation conform: the author-nominee and the apocryphal author. The theoretical principles of Rhetoric and New Rhetoric support reflection. Finally, virtual authorship is considered as a privileged exercise of the diffusion of the docere, the movere and the delectare.

Keywords: Authorship. Virtuality. Argumentation. Rhetoric. 
Introdução

No universo discursivo midiático-cultural contemporâneo, um acontecimento qualquer se transmuta em evento significativo e exacerba as emoções de um auditório virtual que, com dedos velozes, o reproduz e o espetaculariza em vídeos no Youtube, em conversas no WhatsApp, em registros nos blogs, em postagens no Facebook, no Twitter e em todas as redes sociais e plataformas de comunicação. O mesmo acontecimento gera réplicas, tréplicas, adesão ou protestos veementes, sempre em consonância com a dimensão do sensível social. As emoções, enfim, pululam nervosamente nos meios midiáticos e oradores de todos os tipos, alguns escondidos sob pseudônimos ou nomes alheios, nem sempre preocupados com a apuração do que é divulgado, promovem uma invasão noticiosa que é, grosso modo, incontrolável, uma vez que os processos interativos se dão num espaço frenético, espontâneo e incomensurável. As redes de comunicação, assim, funcionam como um exercício velocíssimo de ação do homem sobre o homem. Qualquer evento do mundo é registrado em vários gêneros discursivos, imediatamente divulgado e não existe uma hierarquização do supérfluo ou do fundamental: oradores de toda lavra adaptam o material informativo disponível de acordo com sua percepção de mundo, seus jogos de interesse, seus mitos, suas peculiaridades afetivas e, desse modo, tecem o ecossistema cultural. Tornam-se, assim, autores.

\section{Formas e condições de autoria nos meios digitais}

Tomemos por princípio que o publicar na Internet não muda a essência do ato retórico investido. Ainda que o orador possa contar com a imensa facilidade de editoração (letramento digital) e ampliação significativa do auditório, precisa valer-se da retoricidade 1 para praticar os tria oficia: docere, movere, delectare ${ }^{2}$. O princípio que rege o escrever, então, mantém-se como sempre foi historicamente: mudam-se os paradigmas em função da evolução da tecnologia, mudam-se os materiais de fixação da escrita no tempo, mas o

\footnotetext{
1 Retoricidade: virtude que tem qualquer texto, em qualquer linguagem de ser persuasivo e dialético (TRINGALI, 2014)

${ }^{2}$ Docere, probare, conciliare: para Cícero, equivale a convencer (Brutus 197, Orator, 21-69, De Oratore 2,121). O sentido mais difundido, porém, é o de Platão: “ensinar”; movere, commovere, flectere: comover, persuadir, sensibilizar; delectare: agradar a faculdade do gosto. "Num discurso, as três tarefas sempre se fazem presente de alguma forma, mas uma delas é dominante" (TRINGALI, 2014).
} 
papiro, o papel ou a tela da Internet registram, como sempre, as experiências criativas, ideológicas, políticas, históricas, filosóficas, sociológicas ou cognitivas do homem. O texto, seja qual for a modalidade fisicamente fixada ou o canal em que é publicado, ainda é o locus mais duradouro de saberes, crenças e valores humanos.

Se a essência autoral permanece inalterada, o modo operativo de criação e publicação exige do autor atributos outros, sintetizados por Leitão (2011) como uma prática discursiva multitarefa, multimodal, intertextual e interdiscursiva. Para esse autor, as novas licenças de publicação de conteúdo na Internet, a possibilidade de remixagem desses conteúdos, a familiarização com a tecnologia disponível na rede mundial de computadores e o surgimento das comunidades virtuais e dos gêneros responsáveis pelo funcionamento discursivo, impedem-nos de "pensar a autoria como algo exclusivamente pertencente a um único indivíduo, nem acreditar que a autoria só é possível a um pequeno grupo de indivíduos produtores de certos discursos." (LEITÃO, 2011, p. 225).

Consideremos que hoje, por força dos avanços tecnológicos, um texto publicado na Internet configura o que Weissberg (2015) chama de “transmissão da presença”, em que a desterritorialização e a telepresença funcionam como orientações fundamentais para configurar um processo imediato de interação. É possível, por exemplo, em muitos sites ou aplicativos, apertar o botão "enviar" para, imediatamente, divulgar uma prática autoral que não exige, do indivíduo comum, uma história autoral, construída ao longo de práticas discursivas sedimentadas no tempo. Desse modo, publicado na Internet ou não, um ato retórico, praticado um dia, em algum lugar por um orador primeiro, acentua, pelo discurso, as fragilidades e as potências de um argumento, realça os valores de verdade ou falsidade, de segredo e de mentira e revela-se potente pela construção do verossímil.

Assim, em qualquer lugar da escala entre o saber, o crer e o fazer social reside um discurso autoral com tentáculos argumentativos e poder controlador. Advindas de profissionais ou não da notícia, da academia, das instituições em geral, das agências publicitárias e do cidadão comum, as informações que circulam velozmente nas redes sociais ou nas plataformas diversas da Internet pretendem, sobretudo, assegurar não apenas o fazersaber, mas, especialmente, o fazer-crer. E crenças sempre englobam um emaranhado de paixões e discursos persuasivos. 
Quando efetivada a crença, o passo seguinte é a incorporação do "dever" inerente às orientações que geraram o crível. Um texto, então, se bem estruturado e legível para um auditório particular, pode disseminar um discurso instituinte, que se introjeta no discurso dominante e transforma-se em instituído e socialmente aceito. $\mathrm{O}$ que se altera fundamentalmente no ato retórico praticado na Internet é a velocidade do ato de persuadir e de convencer, a dimensão ampliada de auditório, o jogo dialético de transformação imediata do auditório em autor, fatores que estimulam a prática-reflexiva do enunciado estratégico em contexto do ponto de vista dos participantes. As práticas linguísticas, porém, permanecem educativas, interpretativas e reguladoras do fazer social. Sites que permitem a interação imediata, então, promovem a mudança de turnos orador-auditório e auditórioorador e, em função da urgência do publicar, descrevem bem a anatomia e fisiologia de um ato retórico singular, característico de nosso tempo, em que o “clima" provoca o argumentar. O gesto interpretativo do auditório, no entanto, permanece, pois convencer ou persuadir estão ligados a critérios pragmáticos (efeitos de sentido), estéticos e éticos.

Há, ainda, como sempre houve, por questões históricas de hegemonia da escrita (agora multimodal) sobre a oralidade (FERREIRA, 2004), um respeito pela autoria presentificada nas cavernas, nos pergaminhos, nos livros e nas telas dos computadores, tablets e celulares. Como sempre foi historicamente, a escrita fixa no tempo o percurso da humanização. O volume produzido e a facilidade de divulgação encontrados na contemporaneidade, porém, são fatores que diferenciam substancialmente o ato de produção textual: há um acentuado "caráter de urgência" que perpassa o espaço comunicativo e, como afirma Bazerman (2015), "usamos a língua em tempo real como parte de dramas interacionais emergentes que se modificam a cada nova palavra proferida.”. Essa urgência, sim, pode abalar, de muitas formas e em graus diferenciados, a credibilidade autoral e, assim, diminuir as distâncias de negociação que levam à persuasão ou ao convencimento. Uma mensagem opinativa no twitter pode abalar seriamente o ethos de um orador, pois, como reforça Bazerman, "a linguagem humana baseia-se na interação e na atividade em contexto e só se torna significativa e dotada de propósito em situações de uso (BAZERMAN, 2015, p.14). Enfim, nas práticas discursivas multimodais, o contexto determina o publicar que, por sua vez, sofre limitações e restrições no que tange ao molde do conteúdo e da forma. Tais contingências, podem 
ser bem ou mal usadas pelo orador e, por consequência, revelar adequação ou descompasso do ato retórico em relação às exigências da situação retórica.

Na Internet, uma espécie de Ágora universal, há sempre um alguém para mostrar um texto e um auditório à espreita, ávido por participar de uma polêmica, pois tem consciência de que todo discurso ou já é uma resposta ou aguarda uma resposta. Não é preciso buscar uma editora para lançar uma ideia revolucionária, científica ou do senso comum. Há, também, uma efervescência discursiva que impulsiona o sentir em sociedade e que constitui a retórica dos vigilantes. Nesse jogo dialético virtual, o autor, identificado ou não, encontra-se, de modo amplo, impossibilitado de localizar especificamente o leitor real, ainda que instaure, na inventio, um leitor virtual. Um aspecto restritivo da autoria na Internet encontra-se justamente na dimensão do interlocutor pretendido: a fácil disseminação espacial e temporal da publicação impede que o autor identifique um auditório preciso e leve em conta, no tecer argumentativo, todos os aspectos ideológicos, morais, filosóficos e sociais daqueles a quem pretende dirigir-se. Por outro lado, o auditório, ainda que nem sempre passível de classificação, é palpável, próximo, vigoroso no imenso debate de opiniões e saberes da Internet.

Autores na Internet, para reduzir as inconveniências espaciais e temporais do auditório, embora não possam limitar o acesso, procuram constituir um auditório virtual mais próximo das comunidades discursivas. termo cunhado pelo britânico John Swales (1990), que analisou a assimilação de discursos e a identificação mútua por grupos que se identificam por meios ocupacionais, de especialidade ou de gostos pessoais. O contato é facilitado porque o grupo domina um determinado repertório de gêneros discursivos, hábitos e experiências comuns. Nesse espaço virtual pratica-se, sobretudo, a retórica dos vigilantes. Neste artigo, de modo bastante amplo e ainda carente de especificidades para cada categoria, destacamos o caráter geral dos vigilantes-oradores e vigilantes-auditório.

\section{O caráter operativo dos vigilantes}

A voz, portanto, está na "rede", termo metafórico associado a um sistema de relações de toda espécie, fixado no imaginário, desde os contos mitológicos, à ideia de tecelagem e de labirinto. A medicina de Hipócrates, ao vincular o termo a "organismo" (todas as veias se comunicam e escoam de uma para as outras) e Descartes, ao descrever a superfície do cérebro 
humano, reforçam a ideia de rede vista como "renda", meticulosamente interligada por inúmeros fios. Em outro plano, rede, como afirma Musso, autor de uma história social e crítica dessa noção, é estrutura elementar das telecomunicações, e "conforme o modo de funcionamento da rede, está-se de um lado ou de outro, pois a metáfora da rede é bicéfala: vigilância da circulação e circulação da vigilância" (MUSSO, 2013, p. 34). Para os propósitos deste artigo, a rede é considerada como uma ferramenta veloz de difusão de cultura, aqui entendida, com Weissberg, como o conjunto dos conhecimentos, crenças, representações e práticas que estruturam o "ser conjunto" de uma sociedade (WEISSBERG, 2013, p. 113).

Por sob a política difusa de divulgação de qualquer fato, ideia, evento de pensamento, novos oradores-autores, vigilantes, conhecidos ou não, reconhecidos ou não, lançam na rede vieses interpretativos sob a capa de notícia, piada, charge, poemas, memes, ditos filosóficos e tantos outros gêneros do discurso. Desse modo, os recursos midiáticos contemporâneos fazem ecoar uma ideia, um argumento, um ponto de vista que convence ou persuade, agrega, desagrega ou, até, manipula nervosamente os menos atentos às artimanhas do discurso. Por mais que os sites de busca e relacionamento restrinjam tematicamente o auditório, sempre há a possibilidade de uma ferramenta de busca indicar outros sites, por meio de hiperlinks ${ }^{3}$ e, na tessitura da rede, diminuir ou ampliar a legibilidade de um texto (em função dos conhecimentos prévios do auditório) e, desse modo, criarem impedimentos para a total preservação da face do autor. Nesse caso, eunoia, phronesis e areté ${ }^{4}$ se fragilizam ou se fortalecem em poucos minutos. Como, para os propósitos retóricos, a eficácia é fundamental, a fragilização do ethos é consequência da impossibilidade de liderar um auditório virtual universal.

Outro fator de restrição da autoria na Internet reside no desaparecimento de um contexto retórico explícito e da determinação meticulosa de sua situcionalidade: os textos viajam pelo tempo e pelo espaço, criam seus próprios contextos e, nesse aspecto, diferenciam-se daqueles da retórica tradicional que girava em torno de problemas do discurso público e privilegiavam questões vitais em contextos políticos e deliberativos

\footnotetext{
${ }^{3}$ Hiperlink: ponto de partida para os links, ligações que remetem o leitor de uma página da Web para outra.

4 Phronesis: sabedoria como virtude do pensamento prático, prudência/ areté: simplicidade, sinceridade; eunoia: imagem agradável de si, benevolência.
} 
(BAZERMAN, 2015). Diante de um texto multimodal que vemos na Internet, uma pergunta sempre se faz presente: de onde vêm e para onde vão as mensagens publicadas na Internet? A perspectiva temática dos sites e sua classificação em científicos, técnicos, noticiosos, humorísticos, de relacionamento etc. são auxiliares para a contenção da polissemia, mas não são suficientes, como dissemos, para a preservação da face do autor que precisa, sempre, transformar o auditório virtual em comunidade discursiva. O espaço e o território de atuação retórica são supostamente conhecidos, mas não inteiramente conduzidos pelo orador.

Para o autor da Internet, então, o controle da situação retórica, da audiência e das expectativas do auditório exigem um domínio autoral que suplanta a forma de autoria tradicional. Nesse sentido, inventio, dispositio e elocutio ${ }^{5}$ assumem configurações distintas e nem sempre objetivas, pois a ausência de actio, de presença física diante de um auditório, prejudica a paralinguagem, a proxêmica e a quinésica, que são artifícios ancilares no ato retórico ${ }^{6}$.

No universo do pathos, é sensível que, em tempos de Internet e de redes sociais, o apelo emocional funcione como um estopim tão ou mais poderoso do que a lógica e a demonstração. Um discurso, velozmente difundido pela Internet, pelos meios de comunicação digitais, pode promover a calma ou insuflar a cólera; pode promover o amor ou despertar o ódio; pode ressaltar a vergonha ou alimentar a impudência. Enfim, todas as paixões, assim como a inveja, a emulação, a compaixão e a indignação (ARISTÓTELES, 2004) são consagradas, em diferentes proporções, a partir de gatilhos retóricos que disseminam, rápida e incontrolavelmente, inumeráveis gêneros discursivos no emaranhado da comunicação de nossos dias. Uma notícia falsa ou uma pseudoinformação científica, se críveis, provocam convulsão social pela inserção do patético no racional. Um autor consciente sabe que a Internet se tornou o maior veículo de disseminação da doxa. Vigilante, o auditório contemporâneo, tão logo recebe uma informação que julga interessante, se transforma em orador no turno seguinte. Insuflada por um vento midiático, que a tudo reveste com uma capa discursiva emocionada, as paixões são excitadas e provocam opiniões que, por sua vez, se alastram na mesma

\footnotetext{
${ }^{5}$ Partes do sistema retórico: invenção, disposição, elocução, ação e memória.

${ }^{6}$ (1) Proxêmica uso e organização do espaço físico; (2) Quinésica, quinésica ou cinésica: ciência que estuda a linguagem corporal, o significado expressivo ou comunicativo dos gestos e movimentos corporais percebidos pelos sentidos visual, auditivo ou táctil, de acordo com a situação; (3) Paralinguagem: modificação das características sonoras da voz.
} 


\section{$\mathrm{El} \square \mathrm{dA}$}

Revista Eletrônica de Estudos Integrados em Discurso e Argumentação, Ilhéus, n. 18, abr.2019.

velocidade. Por meio de um conglomerado de atos retóricos, os acontecimentos são dramatizados, espetacularizados e, desse modo, oradores de todos os tipos e auditórios cada vez mais amplos se veem, interativamente, envolvidos num processo de persuasão generalizado por uma retórica efervescente e fluida.

No plano dos logos, a constituição do verossímil é a mola para acirrar os ânimos. A visão da realidade, em seus diversos prismas de interpretação, é aquilatada não como uma verdade positiva ou realista dada, constatada, mas pela forma como se constrói discursivamente essa mesma realidade no jogo oscilante de discursos que promulgam e asseguram, por meio de estratégias retóricas, os efeitos de verdade. Elogiar, depreciar, dar relevância ou escolher um aspecto parcial de um evento do mundo para exaltar interesses é um exercício muito comum na Internet. Criam-se amigos e inimigos instantaneamente e nem sempre com argumentos pertinentes.

Gestos argumentativos, portanto, imbricam-se nos diversos tons discursivos, nas modulações ideológicas, na construção ou desconstrução de valores e crenças e, velocíssimos, desconhecem força capaz de refrear a difusão hiperbólica ou metonímica de um acontecimento do mundo. Desse modo, discursos geram discursos outros que, igualmente céleres, impregnados de opiniões coerentes ou impertinentes, movimentam o pathos. Como nunca está sozinho, o orador atua nos limites de uma área de valores aceitáveis e atribui ao auditório algumas funções: atuar como juízes, atuar como assembleia ou, ainda, atuar como espectadores.

Essas posições regulam a importância que o orador deve atribuir ao auditório em função do grau de problematicidade da questão. No universo da doxa, um auditório que é somente leitor, amplia a tensividade retórica naturalmente existente na comunicação social. Se o auditório é difuso, múltiplos fatores estão em jogo e não podem ser plenamente controlados: moral, valores em vigor, bom-senso, interesses pessoais e de grupo, intensidade das paixões, capacidade de discernimento daquilo que, na situação proposta, é conveniente, justo, legal, útil, nocivo, vergonhoso ou honrável.

\section{Caráter operativo dos vigilantes}

Como afirma Meyer (1993), os utilizadores da linguagem se apresentam uns aos outros segundo uma distância variável que procuram negociar por meio de 


\section{$\mathrm{EI} D \mathrm{dA}$}

uma questão particular que, indiretamente, os coloca também em questão. Num ato retórico tradicional, com auditório fisicamente presente ou com auditório bem delimitado, pathos, ethos e logos coincidem e nem sempre conseguimos deslindá-los com precisão. Numa dependência direta dos objetivos pretendidos, os sites da Internet acentuam uma modalidade persuasiva de autoria por meio de discursos que, num sentido amplo, podem ser divididos em três formas: discurso autoritário; discurso polêmico; discurso fluido.

\subsection{Discurso autoritário}

Os autores do discurso autoritário são representantes de discursos institucionais que, por possuírem discurso autorizado institucionalmente (o cientista, jurista, o padre, o médico, o professor, o governante...), se valem dessa condição para assegurar os pilares institucionais: o poder, o saber e o fazer. Tais autores esforçam-se na contenção da polissemia e consideram o auditório como instrumento de comando. São assim os sites de Igrejas, os científicos, os governamentais, os de corporações de saúde etc. O discurso autoritário, por sua natureza institucional, científica ou pedagógica, normalmente se sustenta sob raciocínios apodíticos (demonstrativos ou científicos), componentes argumentativos que se valem da dedução. Os raciocínios apodíticos operam com premissas verdadeiras ou que produzem efeito de sentido de verdade. As premissas verdadeiras e certas conduzem a uma conclusão também verdadeira e certa, pois derivada da evidência. O discurso autoritário caracteriza-se pelo conhecimento das causas e necessidades que constituem a demonstração, que é uma espécie de silogismo. A racionalidade apodítica é imperativa, quase indiscutível, ligada ao método científico. Por serem autoritários (no sentido de afirmar uma "verdade"), os apodíticos exploram premissas implícitas, muito comuns nos slogans publicitários.

\subsection{Discurso polêmico}

A antilogia (anti = contra; logos = discurso) é a propriedade dialética da oratória: em redor de qualquer questão, defrontam-se em posições diferentes (TRINGALI, 2013). A Internet tornou-se o canal preferido para essa prática em nossos dias. A antilogia, que promove autores, é um dom da democracia, pois permite o direito de resposta. No campo retórico, no entrechoque, os discursos opostos são sempre considerados sadios, pois proclamam a dialética 
da diferença, em que os oradores defendem posições diversas em torno de uma mesma questão e se instaura a polêmica.

Os autores de discurso polêmico procuram controlar a polissemia, pois se valem de raciocínios apodíticos ou dialéticos para determinar uma verdade aparente como toda a verdade. Bons exemplos de autores de discurso polêmico encontram-se nos sites que nasceram de revistas e jornais impressos e se tornaram também virtuais. Diante de uma notícia de caráter referencial, os autores respondentes valem-se, normalmente, da exploração discursiva que nasce de raciocínios dialéticos (ou prováveis): partem de uma premissa provável, admitida por todos ou pela maioria do auditório, pelos mais notáveis e ilustres sábios e geram uma conclusão razoável, altamente provável, embora não absolutamente certa porque produto de crença, de opinião.

Os raciocínios dialéticos são persuasivos porque concordam com a crença mais comum, com a opinião corrente. Desse modo, quebram a inflexibilidade do raciocínio apodítico e apontam, aparentemente, para mais de uma conclusão possível. Provocam, assim, o debate de ideias. Evidentemente, a forma como as premissas são formuladas remetem à conclusão mais aceitável. Tais raciocínios conclamam a razão, procuram convencer.

Em retórica, liga-se ao convencer (cum + vincere = derrotar o opositor). Em tese, deveria ser construído por meio de provas lógicas: indutivas (exemplos) e dedutivas (argumentos). Nem sempre é assim na Internet quando os fatores emocionais suplantam facilmente os racionais. Tais autores exploram predominantemente o gênero deliberativo. O discurso polêmico toma como valores o útil e o nocivo em busca do bem comum, delibera sobre um fato futuro, aconselha ou desaconselha. O auditório, concluído o discurso, é solicitado a decidir uma questão por meio de um voto real ou potencial. Não é incomum também a presença do gênero judicial, uma vez que o auditório é incitado a julgar um fato passado e valorar com base no justo e injusto. De modo virtual, condena-se ou absolve-se e nesse jogo discursivo há acusação e defesa muito manifestas.

\subsection{Discurso fluido}

Os autores de discurso fluido não expressam preocupação científica ou acadêmica em sentido estrito. Produzem mensagens e mensagens de todos os tipos: autoajuda, frases de efeito, pensamentos filosóficos, reflexões de 
fanáticos, nem sempre com autoria explicitada. São autores que promulgam textos em que os sentidos estão abertos. Há predominância de polissemia. Os autores se expõem ao auditório de modo apaixonado e toda a preocupação é com a produção de sentidos que encantem, que enlevem, que indiquem uma direção mais afetiva do que racional. Raramente pretendem o docere, embora seja possível encontrá-los quando ensinam como fazer uma comida, arrumar uma pia ou arranjar os cabelos. Muitos blogs e vídeos, de modo geral, poderiam caracterizar essa tendência discursiva.

Tanto nos vídeos quanto nos blogs, os autores assumem um discurso autorizado (sou profissional, sou poeta...) e os argumentos da qualidade e da quantidade são abundantes e validam o conteúdo enunciado. Há um esforço para promover a publicização de si e, ao mesmo tempo, reforçar uma aparente coloquialidade, vazada em linguagem objetiva ou poética que, sempre, pretende ser eficaz: comover, agradar com intimidade aparente, construída, que visa o outro, num movimento pendular entre o ethos do orador e as agitações patéticas do auditório. A tônica, enfim, é maximização das emoções, sentimentos, paixões de toda espécie. Essa categoria congrega os autores colaborativos, engraçados, burlescos, despudorados e tantos outros que se manifestam de forma autoral nas redes sociais.

\section{Isegoria, kairós e comunidade discursiva}

Essas três categorias gerais de agentes discursivos só se tornam possíveis por meio de alguns recursos fundamentais da democracia:

A "isegoria" é uma descoberta da democracia ateniense que decorre da isonomia. A isonomia é a igualdade de todos perante a lei. Por isegoria se entendia a igualdade de direito que tinha todo cidadão de tomar a palavra numa assembleia e exprimir a própria opinião. "Não há mais tirano efeito que padecer e calar", comenta poeticamente a questão Gregório de Matos. (TRINGALI, 2014, p. 33)

Assim, a Internet congrega os homens numa grande assembleia em que a isegoria é a tônica. Quase incontrolável num espaço cibernético em que todos têm o direito de autoria e de editoria é a observação dos princípios da adequação (prépon = o que convém; kairós = no momento oportuno). A lógica do autor virtual pode não ser aquela contida no Órganon aristotélico (ARISTÓTELES, 2010): demonstrar a verdade, argumentar a favor ou contra uma opinião e desmascarar os sofismas. Nem sempre é assim evidentemente, mas em muitos casos o raciocínio se compõe, sim, de juízos, mas a 


\section{$\mathrm{EI} \square \mathrm{dA}$}

constituição de premissas não pontua, rigorosamente, uma proposição em que a evidência se ressalte para provocar adesão. Nem sempre a conclusão decorre automaticamente das premissas na relação entre antecedente e consequente, principalmente quando são exortadas as paixões em uma comunidade sobretudo discursiva.

\section{Categorias discursivas}

Isegoria, isonomia e kairós conformam uma comunidade discursiva e revelam, de modo amplo, a vocação enunciativa dos autores na Internet.

\subsection{Autor nominado}

Articulistas dos jornais e revistas online são profissionais da escrita, identificam-se e assumem o seu dizer. Os autores de site, blog e twitter, do mesmo modo, são nominados, com um ethos passível de ser autenticado e classificado numa hierarquia de reconhecimento social. Normalmente, encontram-se em suportes temáticos e comunidades discursivas e como os autores determinam um leitor virtual muito específico em preferências e valores, escrevem em consonância com os desejos e interesses daqueles a quem pretendem atingir: um auditório particular. Sites de empresas, de instituições, jornais e revistas online também possuem autores nominados e auditório conhecido. Alguns, com manifesta vocação para o docere, valem-se de hipertextos e remetem, por convite para um clique no lado esquerdo do mouse, o leitor para inúmeros outros sites e outros textos, de acordo com os supostos interesses do leitor na perspectiva do autor. Enfim, seja qual for o suporte comunicacional, o autor identificado é responsável pelo seu dizer e pode ser louvado, ignorado ou reconhecido por sua produção verbal ou não verbal. O texto, assim, nunca recebe um ponto final, pois sempre aponta materialmente para outros e, pela superposição de textos, pode gerar outros de autoria coletiva.

\subsection{Autor apócrifo}

Etimologicamente, apócrifo é um adjetivo qualificativo, de origem no termo grego apokryphos, que significa oculto, não explorado. É preciso considerar duas nuances do significado desse termo para conceituar essa denominação de autoria: primeiramente, a palavra pode significar a ausência 
de assinatura, de autenticação de um documento, que possui origem desconhecida. Pode também significar falso, suspeito, de origem falsa ou duvidosa, sem autenticação. As duas acepções são válidas para essa categorização de autoria na Internet. A facilidade em recortar e colar na Internet sempre abre espaço para publicação de uma série de gêneros e exercícios de autoria nada convencionais. Inominados ou falsamente identificados, muitos textos são postados no Facebook ou enviados por e-mail, WhatsApp e qualquer rede social. Sem assinatura, sem confirmação bibliográfica, ou qualquer identificação, muitos deles circulam na Internet sem que possamos saber de onde vêm, quando foram criados, embora possamos descobrir seus propósitos. O criador primeiro e efetivo se esvanece e o texto fica à mercê dos interesses de um pseudoautor, incerto, colateral, sem vínculo com a referência primeira.

Distribuídos velozmente e de forma difusa, atingem auditórios não específicos em qualquer sentido: circulam na Internet, por exemplo, muitas frases de efeito com autoria atribuída a filósofos famosos, mas que não foram necessariamente escritas ou faladas por eles. São pequenas exortações para encontrarmos a felicidade no cotidiano, ou termos um bom dia ou boa noite ou ainda aderirmos a um movimento social. Mensagens assim, normalmente, vêm impressas em meio a cuidadosa produção gráfica, com figuras e cores, sem, porém, identificação do autor. Amplia-se (sem identificar autoria) ou divulga-se por meio do recortar, colar e enviar.

\section{Autoria virtual: exercício privilegiado do docere, do movere e do delectare:}

Quando se considera a Internet como um instrumento de difusão do docere, é fácil constatar que muitos dela se valem para ensinar e escrevem manuais ou postam no YouTube vídeos sobre como instalar uma válvula de descarga, como levantar corretamente uma parede ou deixar a pele mais viçosa e tornam-se autores-professores pela difusão de conhecimentos. Poetas e cronistas deixam na tela dos computadores seus dotes artísticos. Revoltados anônimos se insurgem sobre seja lá o que for e protestam altiloquentemente nos meios digitais. Espertalhões conquistam pessoas nos chats por processos de sedução nada convencionais. Os novos autores na Internet são, sobretudo, operativos. São, por exemplo, autores de revistas científicas que ficariam escondidas nas bibliotecas universitárias, que se tornam acessíveis em um toque no mouse e revelam estudiosos de todos os 


\section{$\mathrm{El} \square \mathrm{dA}$}

assuntos. Teses, dissertações e monografias postadas nas bibliotecas virtuais revelam autores, propagam temas acadêmicos e facilitam o acesso a pesquisas sobre todas as áreas do conhecimento.

Um aspecto fundamental dessa reflexão reside na crença de que todo ato de linguagem serve não apenas para informar, para comunicar algo, mas, sim e antes de tudo, para influenciar, para persuadir. Considera-se que a linguagem se situa entre dois polos: o da influência e o da ação. Quem influencia tem em mente levar alguém a agir, a executar algo, a provocar uma transformação de um estado inicial. Esse é um conceito aceitável para o que se entende por ato de argumentar. Segundo Perelman e Olbrechts-Tyteca (1996, p. 61), a "argumentação é uma ação que tende sempre a modificar um estado de coisas preexistente". E essa transformação se dá pelo discurso, pelo manuseio dos recursos linguísticos que a língua nos oferece.

A argumentação, como ação discursiva e comunicacional, configura-se como um ato essencial da atividade humana: todo homem, ao agir sobre o mundo e os outros, pratica a argumentação, pois, por ser dotado de opiniões, crenças, valores, esforça-se por influenciar as pessoas para que partilhem iguais concepções. No cerne do argumentar há uma questão fundamental que precisa ser negociada e discutida. Meyer (1993), que compõe um quadro amplo sobre a ciência e a arte da retórica desde a Antiguidade até os nossos dias, destaca que a utilização mais notável da retórica encontra-se, hoje, na propaganda e na política. De modo enfático, situa os caminhos argumentativos num princípio de questionamento e interrogatividade inalienável do ato de persuadir. Onde há uma questão (e sempre existe), há a necessidade de negociação das distâncias e há muitas formas retóricas de atingir o desejado.

Por sua dinamicidade natural, a argumentação compreende sempre uma mudança, tende a modificar o contexto de recepção, ou seja, as opiniões do auditório. $\mathrm{O}$ auditório, depois do ato argumentativo, não dispõe simplesmente de uma opinião a mais sobre o que acreditava, mas uma mudança de ponto de vista ou até de visão de mundo. Enfim, pelo menos parte desta visão se liga à força dos argumentos apresentados. Ressaltamos, por fim, que, embora as provas lógicas, racionais, sejam importantes para atingir os objetivos do orador, a argumentação não dispensa os recursos emotivos, ligados à sedução e, desse modo, razão e emoção se interpenetram na constituição do processo argumentativo. Sob esse ângulo, o medo pode ser construído quando reveste as palavras de paixão para provocar ou acentuar outra paixão. Num plano 
mais específico, autores de discursos discursos midiáticos e institucionais são capazes de articular, com menor ou maior precisão, a "mola dos afetos" e da razão. A ação retórica, assim considerada, implica um sujeito falante que se dirige a um auditório porque pretende atingir certo número de objetivos e só possui o discurso como arma de persuasão.

Há, também, entre as intenções do autor na Internet um movimento persuasivo ligado ao delectare e ao movere. Como autores virtuais, colocam o auditório em posição de assembleia, de espectador para apreciar o discurso. Os textos ligam-se ao agradar, que corresponde, na terminologia latina, a placere: seduzir, encantar, deleitar. O discurso é persuasivo pela exploração do gênero laudatório, pela excitação da afetividade e, desse modo, pode levar o auditório a aderir ao ponto de vista do orador. Os autores que exploram o fluido, normalmente, valem-se do registro informal da linguagem e a intimidade mostrada é um processo de autoria que demanda novos autores, pois permite a participação livre de interessados em comentar, mostrar também suas criações, manifestar-se favoravelmente ou não, opinar e convidar pessoas interessadas para que visitem outros blogs ou sites temáticos.

\section{Considerações finais}

Enfim, escrever na Internet é participar de um processo em que o autor é colocado em relação com o outro e com os outros em busca de uma identificação não mais particular, mas coletiva, para vincular alteria, uma identidade construída com o outro. Ser autor na Internet é praticar a liberdade de mostrar-se diante do outro, num mundo de opiniões conflitantes. É admitir, na efervescência e velocidade midiática, o campo discursivo da verossimilhança, em que as verdades construídas no discurso não são irrefutáveis. É praticar a retórica para imprimir os diversos aspectos laudatórios a um dado assunto, às vezes sob um ângulo de visão muito autoritário, mas nem sempre autorizado.

Ser autor na Internet é assumir um processo de autoria objetivamente ligado ao relacionamento do sujeito com a linguagem, em determinadas condições sócio históricas, e com o meio utilizado para a divulgação de seu texto. Para a retórica, todo o processo de autoria perpassa a constituição do ethos do orador numa relação sobretudo dinâmica com seu auditório. Há, sob a superfície textual, intencionalidade, desejo de comover, agradar, ensinar e 
de persuadir velozmente. O autor na Internet é agente e dinâmico e a emoção é a mola propulsora para a constituição tanto de autores vigilantes quanto de auditórios vigilantes e virtuais.

\section{Referências}

ARISTÓTELES. Arte poética. Tradução: Pietro Nassetti. São Paulo: Martin Claret, 2004. . Órganon. Tradução: Edson Bini. Bauru: Edipro, 2010.

BAZERMAN, Charles. Retórica da Ação Letrada. Tradução: Adail Sobral, Ângela Maria Paiva Dionísio, Judith Hoffnagel, Pietra Acunha. São Paulo: Parábola, 2015.

FERREIRA, Luiz Antonio. Oralidade e Escrita: um diálogo pelo Tempo. São Paulo: Efusão, 2004.

LEITÃO, André Alexandre Padilha. Formas e Funções da Autoria na Internet: uma Prática Discursiva. 2011. Tese (Doutorado em Letras) - Universidade Federal de Pernambuco, 2011.

MEYER, Questões de Retórica: Linguagem, Razão, Sedução. Tradução: Antonio Hall. Lisboa: Ed. 70, 1993.

MUSSO, Pierre. A autoria na Rede. In: PARENTE, André (Org.), Tramas da Rede: novas dimensões filosóficas, estéticas e políticas da comunicação. Porto Alegre: Sulina, 2013. p.17-38.

PERELMAN, Chaïm; OLBRECHTS-TYTECA, Lucie. Tratado da Argumentação: a nova retórica. Tradução: Maria Ermantina G. G. Pereira. São Paulo: Martins Fontes, 1996.

SWALES, John Malcolm. Genre Analyzis: English in Academic and Research Settings. Cambridge: Cambride University Press,1990.

TRINGALI, Dante. A Retórica Antiga e Outras Retóricas: a retórica como crítica literária. São Paulo: Musa, 2014.

WEISSBERG, Jean-Lois. Paradoxos da Teleinformática. In: PARENTE, André (Org.). Tramas da Rede: novas dimensões filosóficas, estéticas e políticas da comunicação. Porto Alegre: Sulina, 2013. p. 113-141.

\section{Forma de citação sugerida}

FERREIRA, Luiz Antônio. A retórica dos vigilantes: autoria online. EID\&A - Revista Eletrônica de Estudos Integrados em Discurso e Argumentação, Ilhéus, n. 18, p. 7489, abr.2019. DOI dx.doi.org/10.17648/eidea-18-2314. 